\title{
Travel Time Analysis of an Open-Rack Miniload AS/RS under Class-Based Storage Assignments
}

\author{
Mohammadreza Vasili and Tang Sai Hong
}

\begin{abstract}
Automated storage and retrieval system (AS/RS) is one of the major warehousing systems, which is widely used in distribution centers and automated production and can play an essential role in modern factories for work-in-process storage, as well asin integrated manufacturing systems. In this study an open-rack miniload AS/RS with unidirectional-upward mobile loads within the rack is considered. In this system, the stacker crane is used for the retrieval operations and shuffling procedures, while the storage operations are carried out by separate devices namely, storage platforms. The proposed AS/RS has one storage platform for each rack to unload several loads at the same time into the rack. Travel time of the proposed AS/RS is analyzed under class-based storage policy by means of Monte Carlo simulation. The results of this study can be used as guidelines for the design and analysis of this kind of AS/RS.
\end{abstract}

Index Terms-Automated storage and retrieval systems (AS/RS), Open-rack miniload AS/RS, travel time, monte carlo simulation.

\section{INTRODUCTION}

Automated storage and retrieval systems (AS/RSs) can be defined as a combination of equipment and controls which automatically handle, store and retrieve materials with great speed and accuracy, without direct handling by a human worker. AS/RSs offer the advantages of improved inventory control and cost-effective utilization of time, space and equipment [1].

The basic components of the AS/RS are storage racks, stacker cranes, input/output (I/O) stations(pickup/delivery, $\mathrm{P} / \mathrm{D}$ stations or docks), and interface conveyors [2]. Groover [3] distinguished six types of $\mathrm{AS} / \mathrm{RS}$; unit load $\mathrm{AS} / \mathrm{RS}$, deep-lane AS/RS, miniload AS/RS, man-on-board AS/RS, automated item retrieval system, and vertical lift storage modules (VLSM).In this regard, if the unit-loads are bins, then the system is generally called a miniload AS/RS [4]. Miniload AS/RS is used to handle small loads (individual parts or supplies) that are contained in small containers, bins or drawers in the storage system [3].

In conventional $\mathrm{AS} / \mathrm{RSs}$, stacker cranes are used to store and retrieve loads into or from the storage cells. Performance of a conventional AS/RS can be enhanced when the ratios of storage and retrieval operations are approximately equally distributed and in this case, a single-shuttle stacker crane can operate up to dual command cycle [5].

For an $\mathrm{AS} / \mathrm{RS}$, the throughput performance (i.e., the

Manuscript received May 28, 2014; revised August 26, 2014.

M. R. Vasili is with the Department of Industrial Engineering, Lenjan Branch, Islamic Azad University, Esfahan, Iran (e-mail: vasili@iauln.ac.ir).

S. H. Tang is with the Department of Mechanical \& Manufacturing Engineering, Faculty of Engineering, Universiti Putra Malaysia, Selangor, Malaysia (e-mail: saihong@upm.edu.my). number of storages or retrievals performed per period) can be increased by minimizing the system travel time which also results in reducing AS/RS operating costs [5]. One strategy to increase the throughput performance of an $\mathrm{AS} / \mathrm{RS}$ is to handle more loads at one time. In a balanced system, the ratios of storage and retrieval operations are equally distributed and therefore the inbound work-flow is equal to the outbound work-flow [6], [7].

Under a balanced situation, for instance, a single-shuttle stacker crane can operate up to dual command cycle (i.e., one storage operation and one retrieval operation are performed in a cycle) [8]. It is important to recognize that the possibility of performing dual command cycles depends on the availability of both storage and retrieval requests [4]. However, considering dynamic nature and realistic operating characteristic of an AS/RS, the ratios of storage and retrieval operations are not distributed equally during certain time slots, and the system operates under an unbalanced situation [7]. A perfectly balanced system is a very idealized situation which is unlikely to occur in real storage systems [6].

Another strategy which can result in minimizing the $\mathrm{AS} / \mathrm{RS}$ travel time and consequently increasing its throughput performance is to use the load shuffling procedures. An AS/RS needs to store and retrieve loads in the shortest possible time period. In order to retrieve loads as quickly as possible, a solution is to shuffle (pre-sort/rearrange) the loads to specified locations to minimize the response time of the retrieval operation. However, very little information about load shuffling can be found in the literature [9].

\section{OPEN-RACK MiNILOAD AS/RS}

In this paper an open-rack miniload AS/RS with unidirectional-upward mobile loads within the rack Fig. 1 is analyzed, in which the stacker crane is only used for the retrieval operations and the storage operations are carried out by separate devices, namely, storage platforms (see [10] for details). The separation of the mechanisms for storage and retrieval operations provides more freedom for the stacker crane to get involved in shuffling operations. This warehousing system has one storage platform for each rack to unload several loads at the same time into the rack. The stacker crane shuffling procedures are used to provide more available locations for increasing the storage capacity of the storage platform. Under such circumstances, the system is enabled for handling several incoming items at the same time (under both balanced and storage-oriented unbalanced situations), thereby increasing the system performance. A detailed description of shuffling procedures in the open-rack miniload AS/RS can be found in [10], [11]. 


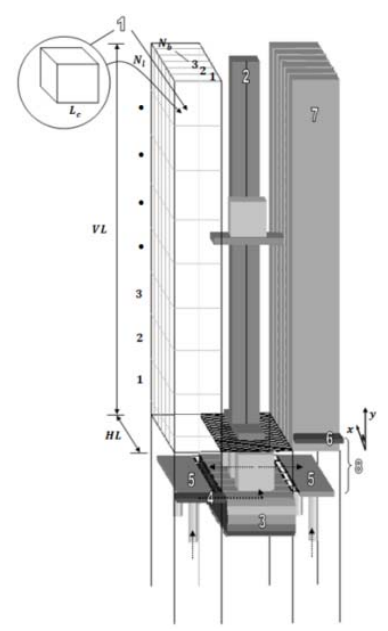

(a)

1. Storage location

2. Stacker crane

3. Asynchronous conveyor

4. Conveyor input point

5. Storage Platform

Fig. 1. (a): Open-rack miniload AS/RS and (b): Open-rack structure.

\section{TRAVEL TIME ANALYSIS}

\section{A. Assumptions and Notations}

The following assumptions are made in this paper:

1) The stacker crane operates on single command basis; the dwell-point positions for the stacker crane and the SP are the output station and the lowest point of the handover station, respectively;

2) There are no technical problems for the construction of the proposed open-rack AS/RS;

3) The output station is located at the lower left-hand corner of the rack. The rack input point is handover station, which is the lowest level of the rack.

4) The accelerations and decelerations of the stacker crane and SPs and the load transfer times can be ignored without affecting the relative performance of the control policies;

5) Randomized storage assignment is used. All the requests are served on FCFS basis.

6) There are no concurrent movements of the stacker crane and SP for different requests.

Furthermore, the following notations are used in this study:

$N_{l}, N_{b}$ number of levels and bays of an open-rack AS/RS, respectively

$N \quad$ total number of cells in the rack $\left(N_{l} \times N_{b}\right)$

$S P \quad$ storage platform

$T_{p}, V_{p}$ travel time and average speed of storage platform, respectively

$M_{p} \quad$ movement or the distance traversed by the storage platform

$v v, h v$ speed of stacker crane for vertical and horizontal movement, respectively

$V L, H 1$ height and length of the rack, respectively

$H_{h}, H_{s}$ height of handover station and standard containers, respectively

$T_{v} \quad$ the time to reach the top of the rack vertically

$T_{h} \quad$ the time to reach the end of the rack horizontally

$d, L_{c}$ spaces between standard containers and width of bays, respectively

$\delta, \rho$ ratio for storage operations and shape factor, respectively

$H_{a}, H_{k}$ vertical height of load-arm when it is maximally open and the backup space, respectively.

$\alpha, b \quad$ ratio for storage and shape factor, respectively

\section{B. Travel Time Model under Randomize Storage [10]}

The objective is to shuffle the loads and at the same time minimize the travel time of storage operation. Therefore, the lower bound $M_{p}$ is used to obtain the total travel time of the SP for the storage operation,

$$
T_{p}=\left(2 / V_{p}\right)\left[H_{h}+\left(N_{l}-1\right) d+\left(H_{a}+\delta\right)\right]
$$

As different expressions must be used to obtain the expected travel time for a storage operation and a retrieval operation, it is necessary to distinguish the operation type in order to obtain the formula to describe the expected travel time [12]. The formula is,

$$
E[T]=P(s) E\left[T_{s}\right]+P(r) E\left[T_{r}\right],
$$

where $T, T_{s}$ and $T_{r}$ are random variables. $T$ is the cycle time for the stacker crane and SP to complete an operation. $T_{s}$ indicates the time spent if the current job is storage, while $T_{r}$ is the time used for a retrieval operation. Obviously, $E[T]$ denotes the expected travel time for one operation. $E\left[T_{s}\right]$ gives the expected travel time if the current job is a storage operation and $P(s)$ is the probability of the current job to be a storage operation. $E\left[T_{r}\right]$ and $P(r)$ are similarly defined for the case of retrieval. By definition, $P(r)=1-P(s)$. Assume that the ratio for storage operations is $\alpha$ in an arbitrary finite job sequence thus,

$$
\begin{gathered}
P(s)=\alpha \\
P(r)=1-P(s)=1-\alpha \\
E[T]=\alpha \cdot E\left[T_{s}\right]+(1-\alpha) \cdot E\left[T_{r}\right] .
\end{gathered}
$$

Under randomized storage assignment, the probability of accessing any cell is identical. Let $N$ denotes the total number of cells in the rack. Therefore, based on Bozer and White [13], a straightforward way of deriving the expected travel time for an AS/RS is to calculate the two-way travel times form output station to every individual cell and take the average of the sum. Thus assuming $t_{r}$ as a random variable to indicate the two-way travel time between the output station and a randomly chosen location in the rack and using the Chebychev travel time (i.e., the travel time of the stacker crane is the maximum of the isolated horizontal and vertical travel times), the stacker crane mean or expected retrieval time can be expressed,

$$
E\left[t_{r}\right]=\frac{2}{N} \sum_{i} \sum_{j} \max \left[\left(\frac{T_{h}}{N_{b}}\right) i, .\left(\frac{T_{v}}{N_{l}}\right)(j-1)\right]
$$

where, $1 \leq i \leq N_{b}, 1 \leq j \leq N_{l}$

Note that, the SP performs the storage operation when it achieves a predefined number of loads, which is referred to as "storage batch size". Let $\rho$ represent the size of this batch, where $1 \leq \rho \leq N_{b}$. Since the batch storage is used, in order to avoid the waiting time in the storage platform, the following method is used. If there is any request for the retrieval of a specific item which is inside the handover 
station, the storage platform should perform the storage operation immediately, regardless of achieving to the full $\rho$. An illustration of required movements for an immediate storage operation is presented in Fig. 2. Same color arrows in Fig. 2 represent concurrent movements. Therefore, there are two types of retrieval operation in the open-rack AS/RS. The first is a normal retrieval operation, where the stacker crane retrieves a load from inside the rack. The second is retrieval operation of a load which is inside handover station and consequently it contains an immediate storage operation. Hence, based on Eqs. (1) and (6), Eq. (7) represents the expected retrieval time of open-rack AS/RS under randomized storage assignment.

$$
E\left[T_{r}\right]=f \cdot E\left[t_{r}\right]+(1-f) \cdot E\left[\max \left(t_{1 . r}, T_{p}\right)+t_{1 . r}\right]
$$

where $t_{1, r}$ is a random variable which denotes the one-way travel time between the output station and a random location in the level 1 of the rack. $f$ indicates the probability that a request from inside the rack takes place and $(1-f)$ represents the probability that a request from inside the handover station takes place. In the case of storage, as mentioned earlier, the operation of the conveyor in the open-rack AS/RS (Fig. 3), to some extent is similar to the carousel storage systems. According to Groover [3] the circumference of conveyor rail $(C)$ is given by following expression, where, $L$ is the length of the conveyor; $H$ is height of the conveyor; $L_{\text {cart }}$ is the length of each cart and $d_{c}$ is the space between carts.

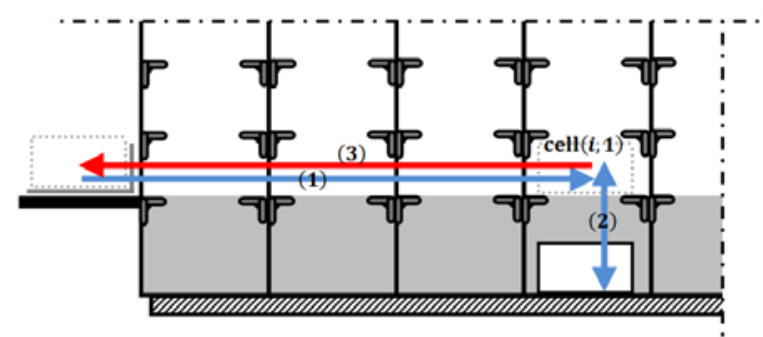

Fig. 2. Required movements for an immediate storage.

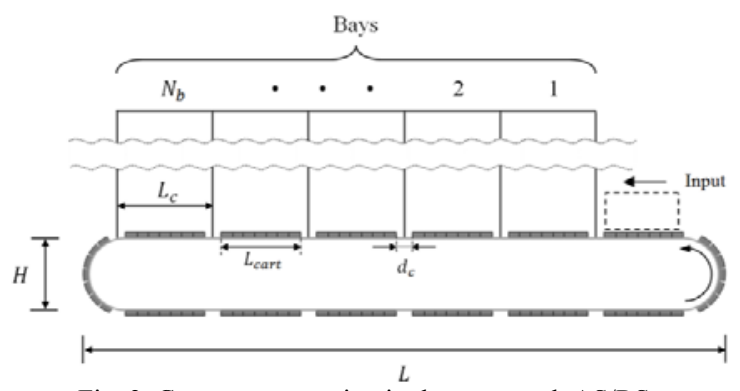

Fig. 3. Conveyor operation in the open-rack AS/RS.

$C=2(L-H)+\pi H$, also $L_{c}=L_{\text {cart }}+d_{c}$ and $\pi H=$ 2. $L_{c}$

Unlike the retrieval operation, for the storage operation the system in enable to handle more than one load per cycle. Hence, depending on the number of loads to be stored, the conveyor handles $\rho_{1}$ loads in each cycle. Let $C_{b}$ denotes the distance traversed by all the loads on the conveyor, up to the point where all carts have released their loads, and $t_{C b}$ represents the time spent for this traversing. The measurement of the distance for obtaining $C_{b}$ is started from input station and finished at the point where all the carts have met all the bays. Assuming $v_{c}$ as the speed of the conveyor (where acceleration/deceleration effects are ignored) hence,

$$
\begin{gathered}
C_{b}=N_{b} \cdot L_{c}+\left(\rho_{1}-1\right) \cdot L_{c}=L_{c} \cdot\left(N_{b}+\rho_{1}-1\right) \\
t_{c b}=L_{c} / v_{c} \cdot\left(N_{b}+\rho_{1}-1\right) .
\end{gathered}
$$

Meanwhile, the stacker crane expected travel time for performing $Z$ shuffling operation sequentially is equal to the expected time for a single-command cycle and $(2 Z-1)$ travel-between times. Therefore,

$$
E\left[T_{s h}\right]=E[S C]+(2 Z-1) E[T B]
$$

where,

$E[S C]$ is the expected single command cycle travel time, $E[T B]$ is the expected travel time between two randomly selected locations (see Bozer and White [13]).

\section{Travel Time Model under Class-Based Storage}

Class-based storage assignment divides the available warehouse space into a number of areas (classes/zones). Each item is subsequently assigned to one of the areas, based on the demand or movements frequency of the items. In practice, the number of the areas is often restricted to three. Random storage is applied within an area [4]. The main advantage of class-based storage is an increased efficiency due to the ability of the system to store the high-turnover items near the $\mathrm{I} / \mathrm{O}$ station. However in comparison, randomized storage is the most commonly used method, since it is simple to administer. In the open-rack miniload AS/RS, when more than one class of items needed to be stored in the rack, by its nature and over the time, the open-rack AS/RS places the items that generate the largest number of movements in the lower levels. This phenomenon will result in faster retrieval of these items and in overall reduce the total travel time of the system. The items with lowest number of movements (seldom requested) are deported to the uppermost levels in the open-rack (see Fig. 4). This natural sorting of loads is referred to as "natural classification" of loads.

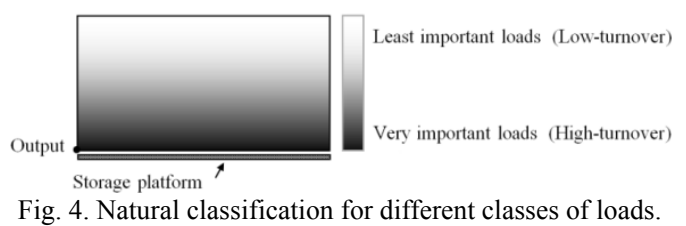

Therefore, in the open-rack AS/RS, for the storage and the retrieval of more than one class of items (when it is required to classify the items' locations in the rack, in order to reduce the average travel time) the loads classification and the class-based storage assignment can be applied by considering two approaches. The first approach is to simply use the conveyor operations, in which for each zone of the rack, the carts only release the assigned items of that particular zone. The second approach is to take into account of the natural classification of loads in the open-rack AS/RS.

Using these approaches, various rack configurations can be considered for implementing the class-based policy in the open-rack AS/RS. Because the random storage is applied within an area in class-based policy, the open-rack AS/RS 
can take advantage of its natural classification when more than one class of items are assigned to each area. Fig. 5 shows an example of the rack configurations for two and three class storage assignments. However, the optimal rack configuration will largely depend on the characteristics of the demand in different applications.

Under class-based policy in order to avoid the waiting time for storage operation of different classes, the predefined storage batch size should be less or equal than number of bays in class A. Therefore, since under class-based assignment the SP deals with fewer loads in compare with randomized storage, it can moves at a relatively higher speed.For the part of the rack where the class B is located at the top of class A, due to the stacker crane shuffling procedure an exact boundary between these two segments is assumed. In this case the shuffling area of stacker crane for class B includes the cells in class A, too. Under the class-based storage assignment, the expected travel time for a single-command transaction in an AS/RS is the weighted sum of travel times of all possible single command transactions [14]. Hence, using the same method as in section A, the expected retrieval time for the open-rack AS/RS under single command cycle and class-based storage assignment can be expressed as,

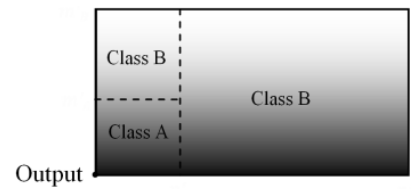

(a)

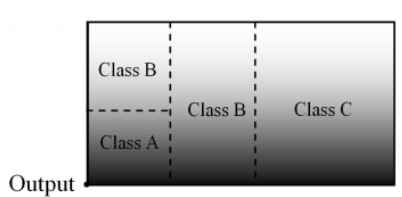

(b)
Fig. 5. Typical rack configuration for two (a) and three (b) class storage assignments in the open-rack AS/RS.

$$
\begin{gathered}
E\left[T_{r}\right]=\sum_{k} P_{k} \cdot f_{k} \cdot E\left[t_{k}\right]+ \\
\sum_{k} P_{k} \cdot\left(1-f_{k}\right) \cdot E\left[\max \left(t_{1 . k}, T_{p}\right)+t_{1 . k}\right]
\end{gathered}
$$

where $k$ denotes the storage zone $(k=$ zone $1,2, \ldots, q)$. $P_{k}$ represents the probability that a movement from zone $k$ takes place. $E\left[t_{k}\right]$ indicates the two-way expected travel time between the output station and a random point in zone $k$. $E\left[t_{1 . k}\right]$ denotes one-way expected travel time between the output station and a random point in the $1^{\text {st }}$ level of zone $k . f_{k}$ indicates the probability that a request from inside zone $k$ takes place. $\left(1-f_{k}\right)$ represents the probability that a request for an item which has been assigned to zone $k$ and is currently inside the handover station takes place. $f_{k}$ and $\left(1-f_{k}\right)$ are calculated using the same methods as used for $f$ and $(1-f)$, based on the total number of the cells in zone $k$ and the storage batch size. For instance, the expected retrieval time for the system under single command cycle and three-class storage assignment is the weighted sum of the travel time of all possible transactions and can be expressed as,

$$
\begin{aligned}
E\left[T_{r}\right]= & \left(P_{1} \cdot f_{1} \cdot E\left[t_{1}\right]+P_{2} \cdot f_{2} \cdot E\left[t_{2}\right]+P_{3} \cdot f_{3} \cdot E\left[t_{3}\right]\right)+ \\
& \left(p_{1} \cdot\left(1-f_{1}\right) \cdot E\left[\max \left(t_{1.1}, T_{p}\right)+t_{1.1}\right]+\right. \\
& p_{2} \cdot\left(1-f_{2}\right) \cdot E\left[\max \left(t_{1.2}, T_{p}\right)+t_{1.2}\right]+ \\
& \left.p_{3} \cdot\left(1-f_{3}\right) \cdot E\left[\max \left(t_{1.3}, T_{p}\right) t_{1.3}\right]\right) .
\end{aligned}
$$

\section{Simulation StUdy}

In this study, for the simulations Monte Carlo simulation method is used under MATLAB ${ }^{\circledR}$, MICROSOFT EXCEL 2007 and Monte Carlo Add-In for EXCEL. However, regardless of their associated complexity, these simulations can be done in any software, numerical computing environment or programming language which is capable of producing random numbers, such as LINGO, BASIC, $\mathrm{C}++$ and so on. The simulation uses randomized number generators for $i$ and $j$ to choose a new destination for each new operation. Then the Chebychev travel time is used (as in Eqs. 6, 7, and 11) to obtain the stacker crane retrieval operation time for this randomized destination. The same method is used for the case of storage operations to obtain the stacker crane shuffling operations time and then the response time for the storage operation of batches of loads are calculated (as in Eqs. 1, 7, and 8). For each operation, the probability that the preceding operation is a storage is set to be $\alpha$ and $(1-\alpha)$ for retrieval operation. A series of 100,000 jobs (which is considerably large compared with the number of cells in an $\mathrm{AS} / \mathrm{RS}$ rack) is executed in each experiment to simulate the infinite batch of jobs. Finally, the travel time of system is calculated through obtaining the average of all simulated results (as in Eq. 2). In order to provide a practical analysis, the general specifications of the system are adapted from KOMATSO miniload AS/RS installed in Technology Park Malaysia (TPM), the center of research and development for knowledge-based industries. The specifications which are used are such that $H_{h}=0.65 \mathrm{~m} ; H_{s}=0.35 \mathrm{~m} ; L_{c}=0.48 ; H_{a}$ $=0.05 \mathrm{~m} ; d=0.01 \mathrm{~m} ; \delta=0.01 \mathrm{~m} ; v v=0.50 \mathrm{~m} / \mathrm{s} ; h v=1.00$ $\mathrm{m} / \mathrm{s} ; v_{c}=1 \mathrm{~m} / \mathrm{s}$; the total number of cells in the rack $\left(N_{l} \times N_{b}\right)$ is $600 ; \rho$ is equal to $N_{A}$ (the total number of bays in class A) and $V_{p}=0.05 \mathrm{~m} / \mathrm{s}$. partial of the results are shown in Table I.

For the three-class storage assignment, products and racks are divided into three classes according to $\mathrm{ABC}$ classification, and partitioning of the rack space is with proportions 20/30/50. In addition to these proportions, for zone A the adjustment is such that the travel time required for the stacker crane to go to the farthest bay from bay 1 to be as close as possible to the travel time required to go to the highest tier from tier 1.Simulation results for the travel time under three-class storage assignment are shown in Table I, when the ABC factor is $20 / 60$. In this Table $x / y \%$ implies that $x \%$ of the items in inventory represent $y \%$ of the total demand and the total number of movements. For example, the ratio $20 / 60 \%$ means that $20 \%$ of the products in the inventory are in class A and satisfy $60 \%$ of total demand. Classes B and C share the remaining demand in equal proportions [14]-[17]. For open-rack AS/RS, simulation results of the travel time under randomized storage assignment can be found in [10].

TABLE I: SimUlation RESUltS FOR TRAVEL TIME UNDER THREE-ClASS STORAGE POLICY $(20 / 60 \%)$ WHEN A $=0.5$

\begin{tabular}{lllll}
\hline $\begin{array}{l}\text { No. of } \\
\text { tiers }\end{array}$ & $\begin{array}{l}\text { No. of } \\
\text { bays }\end{array}$ & $\begin{array}{l}\text { Cells in } \\
\text { rack }\end{array}$ & Shape factor, $b$ & $\begin{array}{l}\text { Travel time } \\
\text { (Sec.) }\end{array}$ \\
\hline 20 & 30 & 600 & 1.0000 & 10.55 \\
15 & 40 & 600 & 0.5625 & 10.69 \\
12 & 50 & 600 & 0.3600 & 11.46 \\
10 & 60 & 600 & 0.2500 & 12.44 \\
8 & 75 & 600 & 0.1600 & 13.94 \\
6 & 100 & 600 & 0.0900 & 17.20 \\
5 & 120 & 600 & 0.0625 & 19.98 \\
4 & 150 & 600 & 0.0400 & 24.25 \\
\hline
\end{tabular}


It can be observed that the general trends of travel time results through varying values of $b$ and $\alpha$ are relatively same as those under randomized storage assignment.

The trend of average storage time is mainly depends on the stacker crane shuffling time and the conveyor travel time. Under the class-based assignment the items should be stored into specified storage zones, while the zones dimensions varies through different values of $b$. Hence, for a fixed shape factor and in comparison with randomized policy, the average number of required stacker crane shuffling operations relatively increases, based on the dimensions of storage zones. However the conveyor travel time relatively decreases, since most of the loads should be stored for class A which is closer to the output station. Meanwhile based on previous discussions, depends on the varying value of $b$, the average storage time may be mostly influenced by the stacker crane shuffling time or the conveyor travel time. According to these observations, through some values of $b$ and $\alpha$, the results under class-based storage policy are higher than the corresponding results under randomized policy. Figures 6 and 7 show the expected travel time versus $b$ and $\alpha$, based on the data presented in Table I and Table II.

TABLE II: Simulation RESUltS FOR TRAVEL TIME UNDER THREE-ClasS STORAGE POLICY $(20 / 60 \%)$ WHEN $b=1$

\begin{tabular}{lll} 
& STORAGE POLICY $(20 / 60 \%)$ WHEN $b=1$ \\
\hline$\alpha$ & Shape factor, $b$ & Travel time (Sec.) \\
\hline 0.0 & 1.0000 & 14.71 \\
0.1 & 1.0000 & 13.95 \\
0.2 & 1.0000 & 13.11 \\
0.3 & 1.0000 & 12.18 \\
0.4 & 1.0000 & 11.31 \\
0.5 & 1.0000 & 10.55 \\
0.6 & 1.0000 & 9.85 \\
0.7 & 1.0000 & 9.23 \\
0.8 & 1.0000 & 8.66 \\
0.9 & 1.0000 & 8.12 \\
1.0 & 1.0000 & 7.62 \\
\hline
\end{tabular}

From Fig. 6 and Fig. 7 it can be observed that with fixed shape factor, the travel time is decreased by the increment of $\alpha$. However in comparison with randomized storage, due to the reductions in the average retrieval travel time and considering the trend of average storage time which was discussed above, for the ABC factor of 20/60, when $\alpha \leq 0.5$, the minimum expected travel time is obtained around $b=1$, whereas when $\alpha>0.5$ the expected travel time improves as the rack becomes non-square and the value of $b$ approaching 0.0625 . Here, the throughput performance of the system is defined as the reciprocal of the average travel time for the $S / R$ mechanism to handle a job [12]. In order to obtain the throughput performance results, for example, according to Table I when $b=1$ and $\alpha=0.5$, the average travel time is $10.55 \mathrm{sec}$. In this regard, the throughput performance can be calculated as $3600 / 10.55=341.23$ loads per hour. Using the same method, the throughput performance results are obtained through different values of $b$ and $\alpha$. All the variations of throughput performance results through different values of $b$ and $\alpha$ can be justified based on the inverse relationship between the through put performance and the expected travel time. The trends of throughput performance through different values of $b$ and $\alpha$ are relatively same as those under randomized assignment, which can be found in [10]. It can be observed that with the fixed shape factor, the throughput performance is increased by the increment of $\alpha$.For the ABC factors form 20/60, when $\alpha \leq 0.5$, the maximum of the throughput performance is obtained around $b=1$, whereas for $\alpha>0.5$, the throughput performance improves as the rack becomes non-square and the value of $b$ approaching 0.0625 .

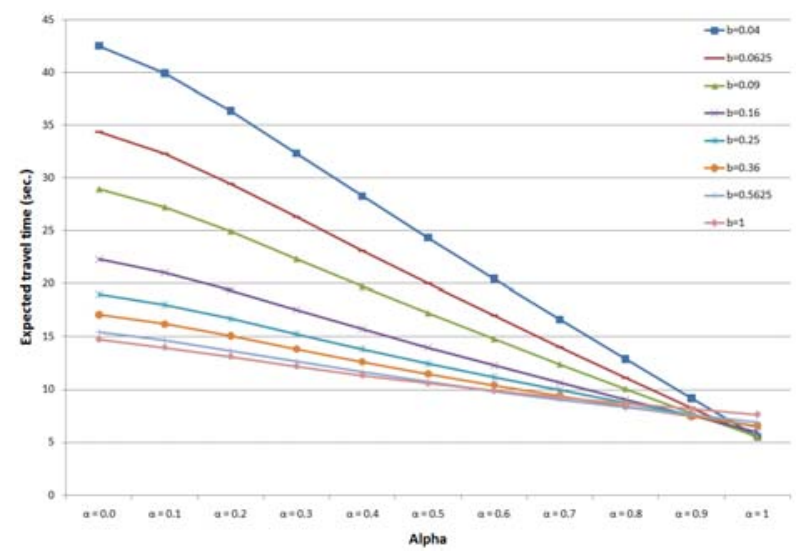

Fig. 6. Expected travel time versus alpha $(\alpha)$ for three-class storage policy when $\mathrm{ABC}$ factor is $20 / 60 \%$.

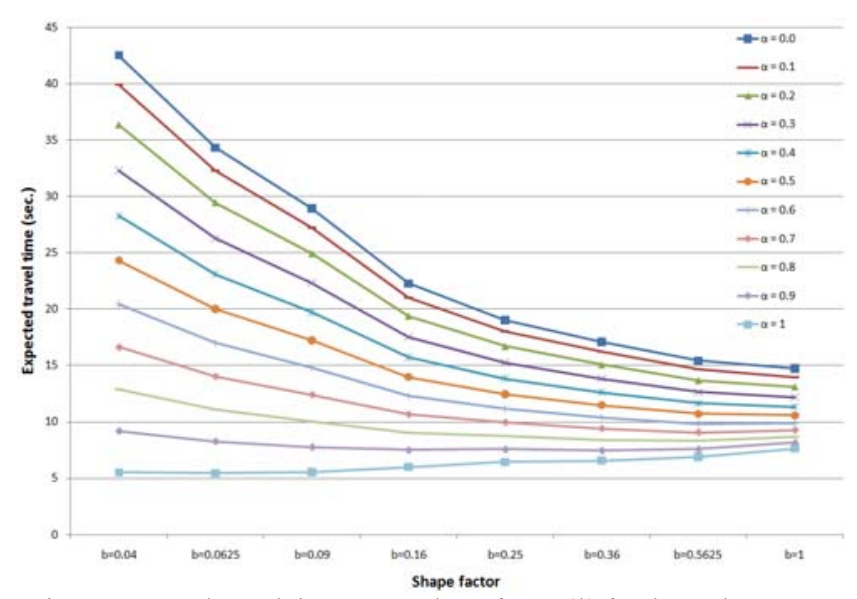

Fig. 7. Expected travel time versus shape factor $(b)$ for three-class storage policy when $\mathrm{ABC}$ factor is $20 / 60 \%$.

\section{CONCLUSION}

In this study an open-rack miniload AS/RS with unidirectional-upward mobile loads within the rack was investigated. Using this mechanism, the average handling time for a batch of jobs can be greatly reduced. The advantages of this AS/RS include high throughput, more flexible AS/RS rack configuration and high fault tolerance. However, the application of this mechanism to the storage of heavy products may be limited. The expected travel time of the proposed AS/RS was analyzed under class-based storage assignment and by using Monte Carlo simulation. These results can be used as guidelines for the design and analysis of this kind of AS/RS. The preliminary evaluation of the authors has shown that by applying the open-rack structure, the travel time and throughput performance of the AS/RS is substantially improved, in comparison with conventional one. Hence, the usage of proposed system is strongly recommended for both randomized and class-based storage assignments. Some recommendations for further studies to expose the potentials of the open-rack AS/RS are to study the policies for request sequencing and the policies for storage assignment under multiple platforms. 


\section{REFERENCES}

[1] M. R. Vasili, S. H. Tang, and M. Vasili, "Automated storage and retrieval systems: A review on travel time models and control policies," Warehousing in the Global Supply Chain: Advanced Models, Tools and Applications for Storage Systems, 2012, pp. 159-210.

[2] R. D. Meller and A. Mungwattana, "Multi-shuttle automated storage/retrieval systems," IIE Transactions, vol. 29, pp. 925-938, 1997.

[3] M. P. Groover, Automation, Production Systems, and Computer-Integrated Manufacturing, 2nd ed. New Jersey: Prentice-Hall, 2001.

[4] K. J. Roodbergen and I. F. A. Vis, "A survey of literature on automated storage and retrieval systems," European Journal of Operational Research, vol. 194, pp. 343-362, 2009.

[5] H. F. Lee and S. K. Schaefer, "Sequencing methods for automated storage and retrieval systems with dedicated storage," Computers \& Industrial Engineering, vol. 32, pp. 351-362, 1997.

[6] M. Goetschalckx and H. D. Ratliff, "Shared storage policies based on the duration stay of unit loads," Management Science, vol. 36, pp. 1120-1132, 1990.

[7] C. Chen, S. Y. Huang, W.-J. Hsu, A. C. Toh, and C. K. Loh, "Platform-based AS/RS for container storage," in Proc. IEEE International Conference on Robotics \& Automation, Taipei, Taiwan, 2003, pp. 181-187.

[8] M. B. M. De Koster, T. Le-Duc, and Y. Yugang, "Optimal storage rack design for a 3-dimensional compact AS/RS," International Journal of Production Research, vol. 46, pp. 1495-1514, 2006.

[9] Y.-H. Hu, W.-J. Hsu, and X. Xu, "Efficient algorithms for load shuffling in split-platform AS/RS," in Proc. IEEE International Conference on Robotics \& Automation, ICRA '04, New Orleans, LA USA, 2004, pp. 2717-2722.

[10] M. R. Vasili and S. M. Homayouni, "Load shuffling and travel time analysis of a miniload automated storage and retrieval system with an open-rack structure," presented at the 41 st International Conference on Computers \& Industrial Engineering, LA, California, 2011.

[11] M. R. Vasili, S. H. Tang, N. Ismail, S. Sulaiman, W. S. Voon, and M. Vasili, "Bead-sort algorithm for load shuffling in miniload AS/RS with an open-rack structure," in Proc. the 39th International Conference on Computers \& Industrial Engineering, Troyes, France, 2009, pp. 1781-1786.
[12] Y.-H. Hu, S. Y. Huang, C. Chen, W.-J. Hsu, A. C. Toh, C. K. Loh, and T. Song, "Travel time analysis of a new automated storage and retrieval system," Computers \& Operations Research, vol. 32, pp. 1515-1544, 2005.

[13] Y. A. Bozer and J. A. White, "Travel-time models for automated storage/retrieval systems," IIE Transactions, vol. 16, pp. 329-338, 1984.

[14] J. Ashayeri, R. M. Heuts, M. Beekhof, and M. R. Wilhelm, "On the determination of class-based storage assignments in an AS/RS having two I/O locations," Material Handling Institute, Charlotte, NC 2002.

[15] W. H. Hausman, L. B. Schwarz, and S. C. Graves, "Optimal storage assignment in automatic warehousing systems," Management Science, vol. 22, pp. 629-638, 1976.

[16] S. Kulturel, N. E. Ozdemirel, C. Sepil, and Z. Bozkurt, "Experimental investigation of shared storage assignment policies in automated storage/retrieval systems," IIE Transactions, vol. 31, pp. 739-749, 1999.

[17] J. Ashayeri, R. M. Heuts, M. W. T. Valkenburg, H. C. Veraart, and M. R. Wilhelm, "A geometrical approach to computing expected cycle times for class-based storage layouts in AS/RS," Tilburg University Disscussion Paper (CentER), vol. 57, pp. 1-32, August 2001.

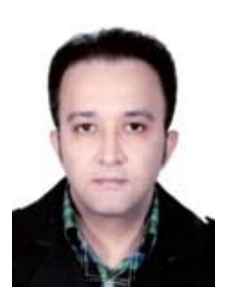

Mohammadreza Vasili is an assistant professor and has been working with Islamic Azad University, Lenjan Branch, since 2010. His main domains of interest are operations research, automated warehousing systems, storage systems, material handlings, transportation and logistics, modeling and simulation.

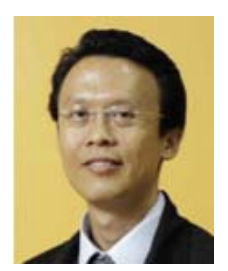

Tang Sai Hong is an associate professor and has been working with Universiti Putra, Malaysia, since 1997. His research and industrial experiences are in the areas of robotics, manufacturing systems engineering, operations research and management, modeling and simulation. 